\title{
Strategi Pengelolaan Kawasan Ekonomi Khusus (KEK) Sei Mangke, Klaster Industri Hilir Kelapa Sawit Terintegrasi dan Berkelanjutan
}

\author{
Muhammad Riza Febriano* \\ Hariyadi** \\ A. Faroby Falatehan*** \\ *Sekolah Pascasarjana IPB Pengelolaan Sumberdaya Alam Dan Lingkungan \\ **Staff Pengajar Fakultas Pertanian, IPB \\ ***Staff Pengajar Fakultas Ekonomi dan Manajemen, IPB \\ Email:dellano@gmail.com
}

\begin{abstract}
Abstrak
Sei Mangkei Special Economic Zone (SEZ) telah dirancang oleh Pemerintah Indonesia sebagai cluster industri untuk industri produk turunan minyak kelapa sawit. Dalam banyak kasus, area terpilih untuk klaster industri berkembang menjadi aglomerasi industri daripada klaster industri. Tujuan makalah ini adalah untuk melakukan analisis manajemen strategis, keberlanjutan dan integrasi pengembangan cluster SEZ Sei Mangkei. Proses hirarki analitik multikriteria (MDM) digunakan untuk menentukan nilai indeks prioritas strategis. Ada yang mempertimbangkan untuk mengukur indeks yang dikategorikan dalam 5 dimensi: regulasi hukum, ekonomi, sosial, lingkungan / ekologis, dan kelembagaan, industri dan teknologi. Indeks skor indeks prioritas keberlanjutan Sei Mangkei SEZ menunjukkan bahwa pengembangan klaster industri tergolong kategori cukup. Indeks terendah ditemukan untuk industri dan teknologi $(0,139)$ dan yang tertinggi adalah dimensi lingkungan / ekologis dan dimensi ekonomi (0,236). Dari analisis leverage, beberapa atribut penting di setiap dimensi ditemukan dan perlu perbaikan untuk meningkatkan strategi pengelolaan Sei Mangkei SEZ menjadi keberlanjutan dan integrasi. Penguatan kelembagaan dan percepatan pembangunan infrastruktur merupakan faktor krusial yang harus diprioritaskan untuk pengembangan klaster industri berbasis kelapa sawit di Sei Mangkei SEZ. Hal ini bisa menjadi rujukan yang signifikan bagi pengambil keputusan, dalam hal ini adalah Pemerintah (BUMN) bekerjasama dengan sektor swasta (penyewa) untuk mengembangkan SEZ Sei Mangkei.
\end{abstract}

Keywords : Sei Mangkei Special Economic Zone (SEZ), Multicriteria Decision Making (MDM), Analithycal Hierarchy Processs (AHP)

\begin{abstract}
Sei Mangkei Special Economic Zone (SEZ) have been designed by Government of Indonesia as industrial cluster for palm oil derivative product industries. In many cases, selected areas for industrial cluster developed into an industrial aglomeration than industrial clustering. The aim of paper was to conduct management strategic, sustainability and integration analysis of Sei Mangkei SEZ cluster development. Multicriteria Decision Making (MDM) analithycal hierarchy processs (AHP) was used to determine the value of strategic priority index. There considered for measuring the index categorized in 5 dimensions : economic, social, enviromental/ecological, laws regulations and institutional, industrial and technology. The index score of sustainability priority index of Sei Mangkei SEZ that showing that the industrial cluster development categorized as sufficient category. The lowest index was found for industrial and technology (0.195) and the highest was environment/ecological dimension and economic dimension (0.236). From the leverage analysis, some critical attributes in each dimensions were found and need improvement to increase the management strategic of Sei Mangkei SEZ into sustainability and integration. Institutional strengthening and accelerated development of infrastructure are the crucial factor should be prioritized for the development of palm oil based industrial cluster at Sei Mangkei SEZ. This could be a significant reference for the decision makers, in this case is Government in cooperation with private sectors (tenant) to develop Sei Mangkei SEZ.
\end{abstract}

Keywords : Sei Mangkei Special Economic Zone (SEZ), Multicriteria Decision Making (MDM), Analithycal Hierarchy Processs (AHP) 


\section{PENDAHULUAN}

Kementerian Koordinator Bidang Perekonomian (2011) dalam rangka menyukseskan Kawasan Ekonomi Khusus (KEK) di Indonesia, perlu adanya pemahaman yang menyeluruh dari berbagai daerah di Indonesia. Untuk itu, kebijakan nasional tentang KEK perlu di pahami hingga level pemerintah daerah setempat (UU No.39/2009). Paparan tersebut antara lain menyangkut pengertian dan fungsi, zonasi, kriteria, tata cara pengusulan, penetapan, pembangunan, skema pembiayaan, sampai pengelolaan dan pelaksanaan, serta evaluasi Kawasan Ekonomi Khusus (PP No.02/2011). Masterplan Percepatan dan Perluasan Pembangunan Ekonomi Indonesia (MP3EI) 2011-2025 secara eksplisit menyebut MP3EI sebagai pedoman paket kebijakan. Merujuk kembali dokumen MP3EI sebagai upaya klasterisasi atau koridorisasi kawasan pertumbuhan ekonomi dengan berbagai kebijakan peraturan serta kerangka kelembagaan kawasan ekonomi khusus (Dharmayanti et al., 2014). Tentu hal ini sangat penting untuk diperhatikan dalam perjalanan implementasi kebijakannya terhadap aspek perlindungan dan pengelolaan lingkungan hidup (UU No.32/2009), sebagaimana visi kebijakan nasional untuk pemerataan pembangunan dalam mewujudkan kesejahteraan dan peningkatan ekonomi tanpa mengabaikan keterpaduan aspek sosial, ekonomi, budaya, dan lingkungan dalam kerangka pembangunan berkelanjutan (sustainable development goals). Indonesia merupakan negara agraris, sekitar $40 \%$ penduduknya menggantungkan hidup dari hasil pertanian. Sejak kemerdekaan hingga saat ini sektor pertanian domestik mengalami pasang surut terhadap dukungan sektor pertanian kepada sektor industri, misalnya dalam hal penyediaan bahan baku. Karena adanya keterkaitan antarsektor pertanian dan industri tersebut, pengembangan industri hasil-hasil pertanian (agroindustri) diharapkan dapat meningkatkan nilai tambah (value added) produk pertanian dan memperluas penciptaan lapangan kerja. Selain itu, agroindustri akan menjadikan produk-produk pertanian menjadi lebih beragam produk turunannya (Soekartawi 1993).

Saat ini semua pihak baik pemerintah, BUMN, swasta, dan masyarakat harus mampu memikul tanggung jawab bersama agar produk pertanian tidak hanya dijual/diekspor secara mentah, melainkan dapat diolah terlebih dahulu sehingga memberikan nilai tambah. Sihaloho dan Muna (2013) Pengertian nilai tambah di sini adalah suatu komoditas yang bertambah nilainya karena melalui proses pengolahan, pengangkutan ataupun penyimpanan dalam suatu produksi. Salah satu kegiatan utama dari di pusat kegiatan MP3EI Koridor I (Sumatera), telah ditetapkan sebagai Kawasan Ekonomi Khusus (KEK) nasional adalah KEK Sei Mangkei yang terintegrasi dengan bisnis utama berupa industri hilirisasi kepala sawit dan karet (PP No.29/2012). Di samping bisnis utama, terdapat beberapa bisnis pendukung seperti logistik, energi, aneka industri dan pariwisata. Industri kelapa sawit di Indonesia telah berkembang pesat dengan dukungan pertumbuhan perkebunan yang sangat pesat pula hingga mengalami peningkatan yaitu dari 133.300 ha pada tahun 1970 menjadi menjadi 8,9 juta ha pada tahun 2012, dan menjadi 11,5 juta hektar pada tahun 2015. Peningkatan luas areal tersebut secara nyata meningkatkan produksi minyak sawit di Indonesia, yaitu dari 216,8 ribu ton pada tahun 1970 menjadi 26,5 juta ton pada tahun 2012, dan 31 juta ton CPO (Crude Palm Oil) pada 2015 (Ditjen Perkebunan 2015). Pemanfaatan CPO (Crude Palm Oil) industri hulu di Indonesia yang masih relatif rendah, sekitar $27,41 \%$ dari 
total produksi CPO nasional (Rifai et al 2014). Oleh karena itu, pada tahun 2011 telah ditetapkan PP No.02/2011 tentang Kawasan Ekonomi Khusus (KEK) Sei Mangkei yang terintegrasi berupa industri hilirisasi kepala sawit dan karet. Produk-produk utama yang dihasilkan di antaranya adalah fatty acid, fatty alcohol, surfactant, biodiesel, dan biogas terintegrasi dan berkelanjutan (Buku 1 Agenda Pembangunan Nasional RPJMN 2015-2019).

Berdasarkan perihal tersebut, bahan baku (kelapa sawit dan karet) yang telah mengalami perubahan nilai karena mengalami pengolahan dapat diperkirakan seberapa besar nilainya. Kelapa sawit saat ini masih luput dari perhatian serius untuk dikembangkan nilai tambahnya, padahal Indonesia memiliki potensi yang sangat besar. Misalnya, sebagian besar hasil panen hanya diolah sampai level crude palm oil (CPO). Oleh karena itu, industri hilirisasi pengolahan produk-produk pertanian khususnya komoditi perkebunan kelapa sawit perlu didukung oleh semua pihak agar nilai tambah yang pada akhirnya dapat meningkatkan pendapatan nasional (Kurniawan 2011). Nilai tambah yang semakin besar atas produk pertanian khususnya kelapa sawit dan karet tentunya dapat berperan bagi peningkatan pertumbuhan ekonomi masyarakat. Pertumbuhan ekonomi yang meningkat tentu saja berdampak bagi peningkatan lapangan usaha dan pendapatan masyarakat yang muara akhirnya adalah pemerataan pembangunan dan perekonomian rakyat (Sihaloho dan Muna 2013). Rachman (2014) Pembentukan Kawasan Ekonomi Khusus (KEK) merupakan fenomena global yang sulit kita hindari, karena KEK merupakan salah satu bentuk baru kerjasama internasional dalam bidang perdagangan sebagai konsekwensi masuknya Indonesia menjadi anggota berbagai organisasi perjanjian perdagangan internasional baik GATT/WTO, APEC, ACFTA maupun IMTGT. Kerjasama KEK saat ini merupakan perkembangan mutakhir dari berbagai bentuk kerjasama ekonomi sebelumnya. Salah satu bentuk kerjasama ekonomi yang pernah dikembangkan pemerintahan sebelumnya adalah pembentukan Kawasan Ekonomi Terpadu (KAPET) di Indonesia (Listiyorini 2006).

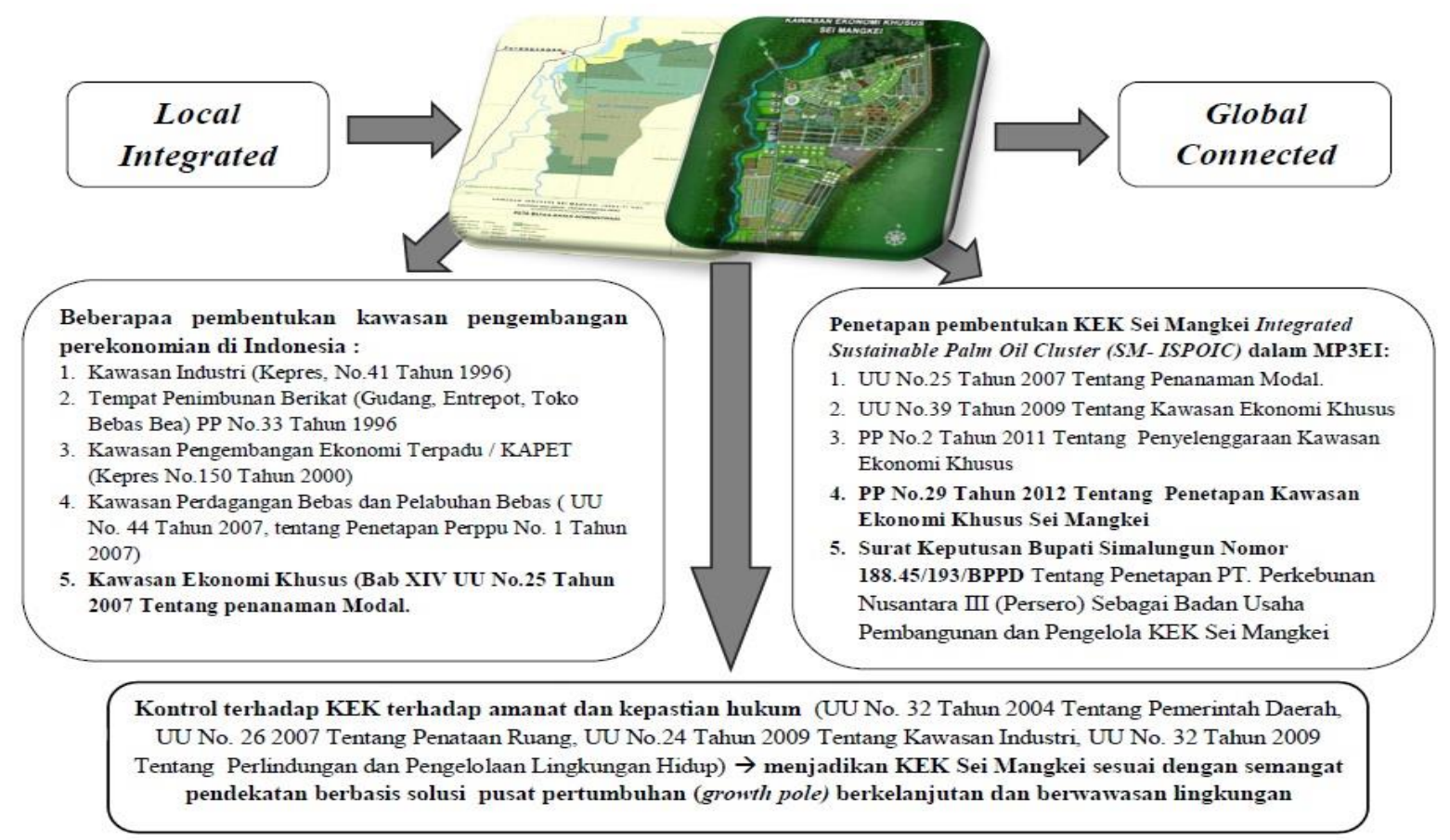

Gambar 1. Diagram kerangka pemikiran penelitian 
Berdasarkan uraian di atas tujuan penelitian ini adalah sebagai berikut, studi kondisi eksisting KEK Sei Mangkei klaster industri hilir terintegrasi, sebagai Kawasan Ekonomi Khusus (KEK) pertama yang ditetapkan pemerintah (PP 29/2012); studi kepentingan dan pengaruh antar stakeholder KEK Sei Mangkei klaster industri hilir terintegrasi dan berkelanjutan; dan merumuskan prioritas strategi dalam pengelolaan KEK Sei Mangkei klaster industri hilir kelapa sawit, menuju KEK terintegrasi dan berkelanjutan.

\section{METODE PENELITIAN}

Tempat penelitian dilakukan di Kawasan Ekonomi Khusus (KEK) Sei Mangkei, Klaster Industri Hilir Kelapa Sawit, PT. Perkebunan Nusantra III (Persero), yang berada dalam wilayah administratif Desa Sei Mangkei, Kecamatan Bosar Maligas, Kabupaten Simalungun, Propinsi Sumatera Utara. Waktu pelaksanaan penelitian dimulai bulan Agustus 2015 sampai dengan Agustus 2016. Bahan yang digunakan dalam penelitian adalah peta desain dasar zonasi KEK Sei Mangkei yang diperoleh dari PT. Perkebunan Nusantara III (Persero). Alat yang digunakan berupa global positioning system (GPS), kuesioner, Software ArcGis dan Expert Choice 11.

Data dan informasi yang dikumpulkan terdiri atas data primer dan data sekunder. Data primer akan diperoleh melalui pengumpulan data dan pengamatan langsung di lapangan terhadap kondisi eksisting dan berbagai kegiatan pembangunan dan pengembangan kawasan yang berlangsung KEK Sei Mangkei, Klaster Industri terintegrasi berkelanjutan. Selain itu data primer diperoleh dengan metode pengumpulan data berupa kuesioner responden pakar sebanyak lima (5) orang pakar, yaitu pakar bidang ekologi/lingkungan, sosial, ekonomi, hukum dan kelembagaan, industri dan teknologi. Alat pengumpulan berupa kuesioner kepentingan dan pengaruh stakeholder dan kuesioner analisis hirarki proses (AHP). Data sekunder diperoleh dari dokumen persyaratan sekretariat Dewan Nasional Kawasan Ekonomi Khusus (KEK), laporan dan dokumen bulanan/semester/tahunan dari lembaga/instansi terkait. Adapun teknik Analisis Data Penelitian yaitu:

1. Studi kepentingan dan pengaruh stakeholder

Metode studi kepentingan dan pengaruh stakeholder merupakan salahsatu perangkat penelitian, menggunakan "stakeholder grid" dengan bantuan perangkat lunak komputer program Microsoft Excel XLSTAT. Hasil analisis stakeholder ini akan memetakan setiap stakeholder berdasarkan kepentingan dan pengaruhnya dalam pengelolaan Kawasan Ekonomi Khusus (KEK) Sei Mangkei. Pemetaan tingkat kepentingan dan pengaruh stakeholder didasarkan pada justifikasi pakar dalam bentuk nilai pembobotan (skoring).

Tabel 1. Penilaian (skoring) kepentingan dan pengaruh setiap stakeholder

\begin{tabular}{|c|lr|}
\hline $\begin{array}{c}\text { Nilai } \\
\text { Skor }\end{array}$ & \multicolumn{1}{|c|}{ Keterangan } \\
\hline 1 & $\begin{array}{l}\text { Tingkat kepentingan dan } \\
\text { pengaruh } \\
\text { rendah. }\end{array}$ \\
\hline 2 & $\begin{array}{l}\text { Tingkat } \\
\text { pengaruh stakeholder sangat }\end{array}$ \\
\hline 3 & $\begin{array}{l}\text { Tingkat } \\
\text { pengaruh stakeholder rendah }\end{array}$ \\
\hline 4 & $\begin{array}{l}\text { Tingkat } \quad \text { kepentingan dan dan } \\
\text { pengaruh stakeholder tinggi. }\end{array}$ \\
\hline 5 & $\begin{array}{l}\text { Tingkat kepentingan dan } \\
\text { pengaruh } \\
\text { tinggi. }\end{array}$ \\
\hline
\end{tabular}

Berdasarkan nilai pembobotan (skoring) tingkat kepentingan dan pengaruh masing-masing stakeholder 
berdasarkan justifikasi pakar tersebut di kelompokkan menurut jenis dan indikatornya, kemudian dipetakan sehingga membentuk koordinat.

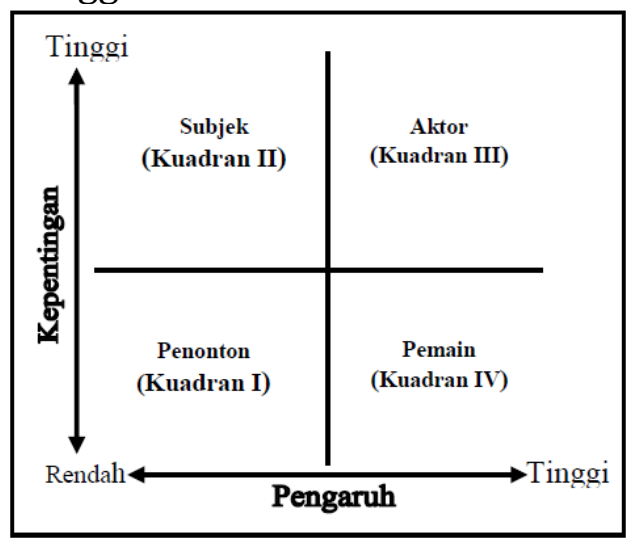

Gambar 2. Kuadran pemetaan stakeholder berdasarkan identifikasi nilai (skoring)

Selanjutnya diterjemahkan ke dalam matriks resultante untuk mengidentifikasikan stakeholder dalam empat kuadran. Posisi pada setiap kuadran dapat menggambarkan ilustrasi mengenai posisi dan peranan yang dimainkan oleh masing-masing stakeholder dalam pengelolaan kawasan, yaitu:

1. Kuadran I adalah penonton yang merupakan kelompok stakeholder yang paling rendah kepentingan dan pengaruhnya.

2. Kuadran II adalah subjek yang merupakan kelompok stakeholder yang penting namun perlu pemberdayaan dalam pengoptimalan kepentingan dan pengaruhnya.

3. Kuadran III adalah pemain yang merupakan kelompok stakeholder yang paling kritis karena kepentingan dan pengaruh yang tinggi.

4. Kuadran IV adalah aktor yang merupakan kelompok stakeholder yang dapat berperan untuk perumusan kebijakan, karena memiliki kepentingan rendah dan pengaruh tinggi dalam pengelolaan kawasan.
2. Analisis hirarki proses (AHP) strategi pengelolaan KEK Sei Mangkei, klaster industri terintegrasi dan berkelanjutan

Metode Analisis Hirarki Proses (AHP) ini disusun dengan memperhatikan konsep-konsep dan model pengembangan kawasan industri terhadap "Strategi Pengelolaan Kawasan Ekonomi Khusus (KEK) Sei Mangkei, Klaster Industri Hilir Kelapa Sawit Terintegrasi dan Berkelanjutan". Disamping itu juga didasarkan pada hasil analisis diagram hirarki kebutuhan dari para pemangku kepentingan (stakeholder) atau disingkat PPK dan strategi pengelolaan Kawasan Ekonomi Khusus (KEK) klaster industri dengan metode partisipatif yang melibatkan pendapat pakar di bidang Kawasan Ekonomi Khusus (KEK) Sei Mangkei. Berdasarkan struktur pembobotan hirarki dengan Skala Saaty (1 sampai 9), nilai dan definisi pendapat kualitatif tersebut (Tabel. 2).

Tabel 2. Penilaian tingkat kepentingan (skoring) antar masing-masing atribut kriteria

\begin{tabular}{|c|l|}
\hline $\begin{array}{c}\text { Nilai } \\
\text { Skor }\end{array}$ & \multicolumn{2}{|c|}{ Keterangan } \\
\hline $\mathbf{1}$ & $\begin{array}{l}\text { Kriteria yang satu dengan } \\
\text { yang lainnya sama penting }\end{array}$ \\
\hline $\mathbf{3}$ & $\begin{array}{l}\text { Kriteria yang satu sedikit } \\
\text { lebih penting (agak kuat) }\end{array}$ \\
\hline $\mathbf{5}$ & $\begin{array}{l}\text { Kriteria yang satu sifatnya } \\
\text { lebih penting (lebih kuat } \\
\text { pentingnya) }\end{array}$ \\
\hline $\mathbf{7}$ & $\begin{array}{l}\text { Kriteria yang satu sangat } \\
\text { penting dibanding Kriteria } \\
\text { yang lainnya }\end{array}$ \\
\hline $\mathbf{9}$ & $\begin{array}{l}\text { Kriteria yang satu ekstrim } \\
\text { pentingnya dibanding } \\
\text { Kriteria yang lainnya }\end{array}$ \\
\hline $\mathbf{2 , 4}$ & $\begin{array}{l}\text { Nilai tengah di antara dua } \\
\text { nilai skor penilaian diatas }\end{array}$ \\
\hline $\mathbf{6 , 8}$
\end{tabular}

Langkah paling awal dalam penggunaan Analytical Hierarchy Process 
(AHP) adalah merinci permasalahan ke dalam komponen - komponennya kemudian mengatur bagian dari komponen-komponen tersebut dalam bentuk hirarki. Hirarki yang paling atas diturunkan dalam beberapa set elemen lainnya, sehingga akhirnya terdapat elemen-elemen yang spesifik atau elemen-elemen yang dapat dikendalikan dicapai dalam situasi konflik (Saaty, 1993). Tahapan dalam analisis data sebagai berikut: (1) identifikasi sistem, (2) penyusunan hirarki, (3) membuat matriks perbandingan/komparasi berpasangan, (4) menghitung matriks pendapat individu, (5) menghitung pendapat gabungan, (6) pengolahan horizontal, (7) pengolahan vertikal dan (8) revisi. Proses Hirarki Analitik (AHP) adalah suatu pendekatan yang biasanya digunakan untuk menganalisis kebijakan, seperti dalam pemilihan kebijakan strategi pengelolaan kawasan ekonomi khusus (KEK) Sei Mangkei, klaster industri hilir kelapa sawit terintegrasi dan Berkelanjutan.

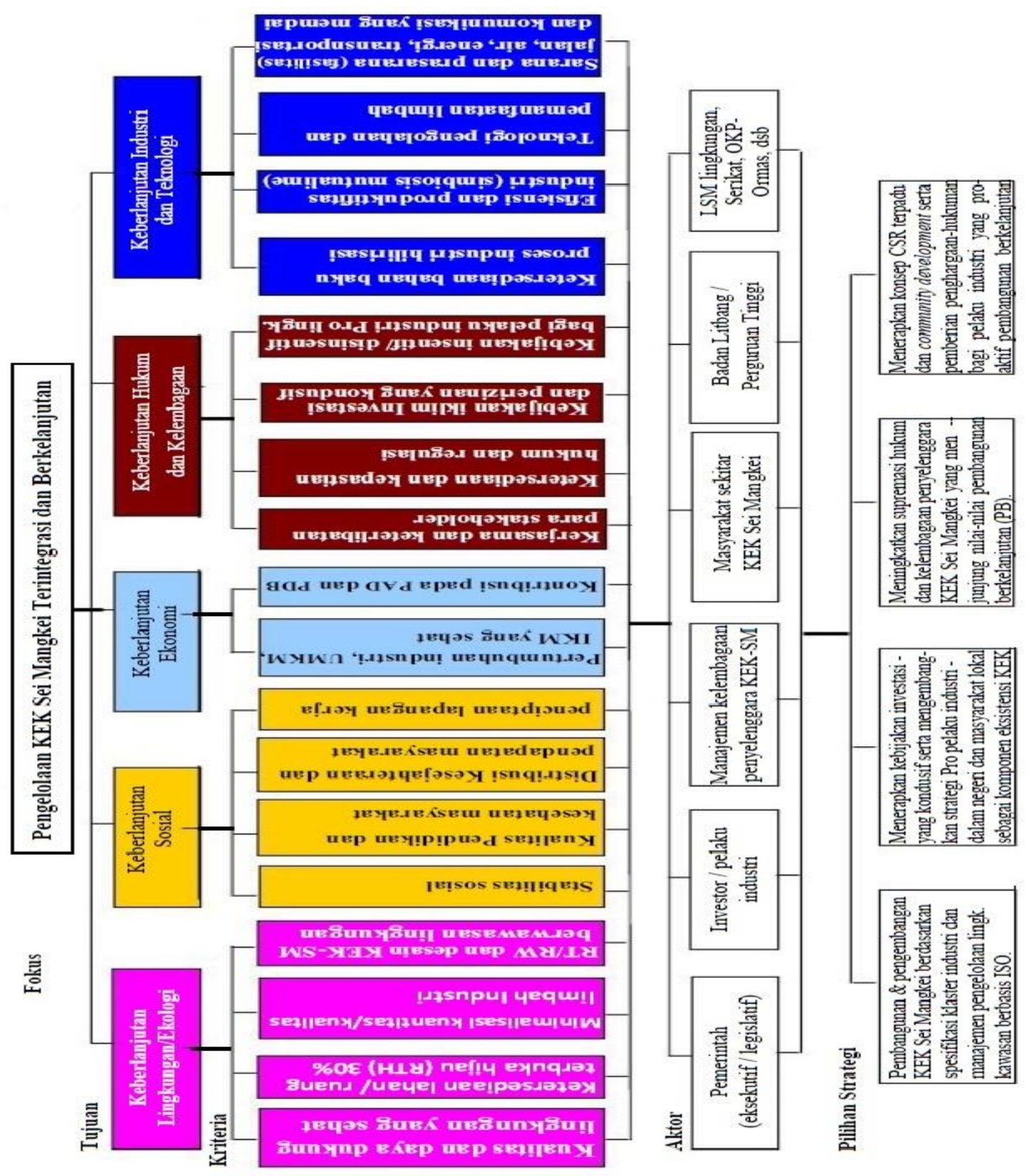

Gambar 3. Diagram Hirarki AHP : Strategi Pengelolaan Kawasan Ekonomi Khusus (KEK) Sei Mangkei. 


\section{HASIL DAN PEMBAHASAN}

\section{Studi Kondisi Eksisting Kawasan Ekonomi Khusus (KEK) Sei Mangkei}

Sejak 27 Pebruari 2012, Sei Mangkei telah ditetapkan menjadi Kawasan Ekonomi Khusus berdasarkan Peraturan Pemerintah Nomor 29 Tahun 2012. Penetapan KEK Sei Mangkei ini didasari bahwa pemerintah memandang perlu untuk mengembangkan kegiatan perekonomian di wilayah Sei Mangkei yang bersifat strategis bagi pengembangan ekonomi nasional. Berdasarkan desain dasar (master plan) KEK Sei Mangkei, terdiri atas tiga zona yaitu zona industri, fasilitas dan zona pendukung. Dari luas keseluruhan Kawasan Industri Sei Mangkei, peruntukan untuk kawasan industri sebesar $69.69 \%$, untuk fasilitas sosial dan umum sebesar $15.77 \%$ dan zona yang berfungsi sebagai pendukung sebesar $\quad 14.54 \% \quad$ (Kementerian Perindustrian 2010). Lokasi KEK Sei Mangkei ini akan difungsikan menjadi klaster industri sebagai kegiatan utamanya dan didukung dengan zonazona penunjang lainnya.

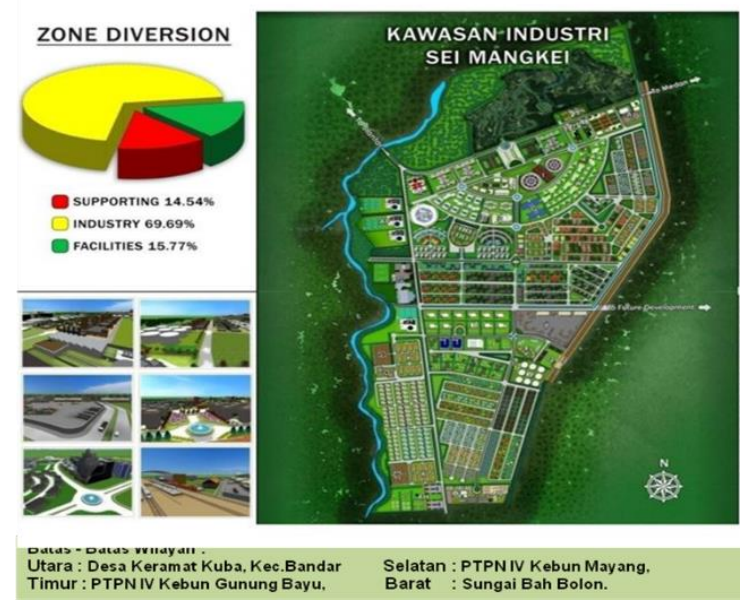

Gambar 4. Masterplan Kawasan Ekonomi Khusus (KEK) Sei Mangkei.

Metode untuk mengetahui kondisi eksisting di kawasan ekonomi khusus (KEK) Sei Mangkei terhadap perubahan penggunaan lahan digunakan metode analisis data sistim informasi geografis (SIG) yang merupakan analisis spasial berbasis pemetaan dan geografi. SIG adalah sebuah alat bantu manajemen berupa informasi berbantuan komputer yang berkait erat dengan sistem pemetaan dan analisis terhadap segala sesuatu serta peristiwa-peristiwa yang terjadi di muka bumi. Untuk mengumpulkan, menyimpan, menggali kembali, mentransformasi dan menyajikan data spasial dan aspek-aspek permukaan bumi, SIG ini dipakai untuk analisis eksisting pembangunan KEK Sei Mangkei. Hasil analisis spasial melalui pemanfaatan data citra ini adalah dalam bentuk peta overlay dari multi layer peta tematik desain dasar zona kawasan KEK Sei Mangkei yang diperoleh dari PT. Perkebunan Nusantara III (Persero). KEK Sei Mangkei berada di Kecamatan Bosar Maligas yaitu di Nagori Sei Mangkei. Secara geografis KEK Sei Mangkei berada

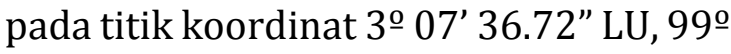
20' 35.85" BT dengan luas total kawasan yang direncanakan adalah seluas 2002 ha. Batas-batas kawasan ini adalah di sebelah Utara berbatasan dengan Desa Keramat Kuba; sebelah Selatan berbatasan dengan PTPN IV (Persero) Kebun Mayang; sebelah Timur berbatasan dengan PTPN IV (Persero) Kebun Gunung Bayu; dan di sebelah Barat berbatasan dengan sungai Bah Bolon.

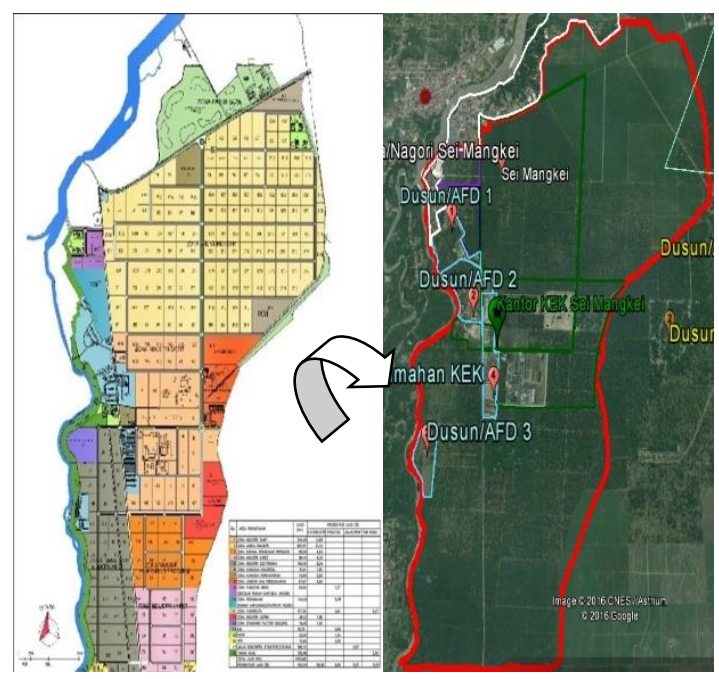


Gambar 5. Overlay data citra satelit dari peta tematik desain dasar (master plan) KEK Sei Mangkei, 2016.

Berdasarkan studi kondisi eksisting hasil penelitian, pembangunan dan pengembangan KEK Sei Mangkei selain berada di areal perkebunan kelapa sawit (sebelum ditetapkan PP 29/2012) telah dibangun pabrik kelapa sawit (PKS) 30 Ton TBS/Jam sejak tahun 1997, yang telah ditingkatkan menjadi 75 Ton TBS/Jam pada tahun 2010. 1) Kantor penyelenggara KEK Sei Mangkei, 2) Pabrik pengolahan kelapa sawit (PKS), 3) Water treatment plant (WTP) kapasitas $250 \mathrm{~m}^{3} / \mathrm{jam}$ dan wasste water treatment plant (WWTP) kapasitas $250 \mathrm{~m}^{3} / \mathrm{jam}, 4$ ) Metering gas dan instalasi jalur pipa gas oleh PT. Pertagas, 5) Tank farm (tangki timbun) sebanyak $2 \times 5000$ Ton crude palm oil (CPO) dan $2 \times 3000$ Ton crude palm kernel oil (CPKO). 6) Gedung pusat inovasi kelapa sawit dan gedung unit pemadam kebakaran. 7) Dry port memiliki kapasitas 5.300 Teus, 8) Gardu induk PLN, 9) Jalan utama sepanjang 4.4 $\mathrm{km}, 10$ ) Jalur kereta api sepanjang 2.95 $\mathrm{Km}$ yang menghubungkan KEK Sei Mangkei dengan jalur kereta api yang telah (Stasiun Perlanaan dengan , 12.) Tahap pembangunan Pabrik (refinery plant, fatty acid plant, fatty alcohol plant), Konsorsium PTPN III dan PTPN IV (BUMN) seluas $25 \mathrm{Ha}$ dengan nilai investasi 3.6 Triliun Rupiah. (Gambar 6.).

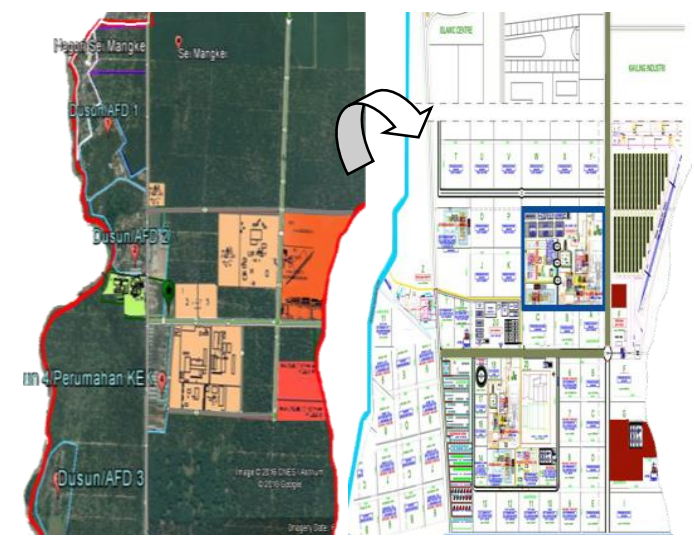

Gambar 5. Detail eksisting overlay data citra satelit dengan peta tematik desain dasar (master plan) KEK Sei Mangkei, 2016.

\section{Studi Kepentingan dan Pengaruh Stakeholder}

Studi kepentingan dan pengaruh stakeholder dalam kajian ini dilakukan untuk memetakan tingkat kepentingan dan pengaruh stakeholder dalam pengelolaan KEK Sei Mangkei. Terdapat 26 stakeholder yang diperkirakan memiliki kepentingan dan pengaruh dalam pengelolaan KEK Sei Mangkei, yaitu : (1) Kementerian koord. Perekonomian, (2) Bappenas - Bappeda, (3) Dewan Nasional, (4) BKPM-D, (5) Kementerian Keuangan,

Kementerian/Dinas Perindustrian, (7) Kementerian/Dinas Perdagangan, (8) LSM, OKP/ ORMAS, (9) Masyarakat sekitar, (10) Pelaku industri (PMA/PMDN), (11) Karyawan perusahaan/Serikat Buruh, (12) Dispenda Prop./Kab. (13) Kementerian PU-PR, (14) Konsultan/Kontraktor (Praktisi), (15) Administrator Kawasan (PTSP), (16) Badan Usaha Pembangunan dan Pengelola (BUPP) - PT. Perkebunan Nusantara III (Persero), (17) Kementerian/Dinas Lingkungan Hidup, (18) Kementerian Dalam Negeri (19) Kementerian/ Dinas Perhubungan, (20) Kementerian/Dinas Tenaga Kerja, (21) Kementerian/Dinas Agraria dan Tata Ruang, (22) DPR RI - DPRD Prop./Kab. (23) Dewan Kawasan, (24) Perguruan Tinggi/Lembaga Penelitian, (25) Konsumen, (26) POLRI - TNI dan sejenisnya. 


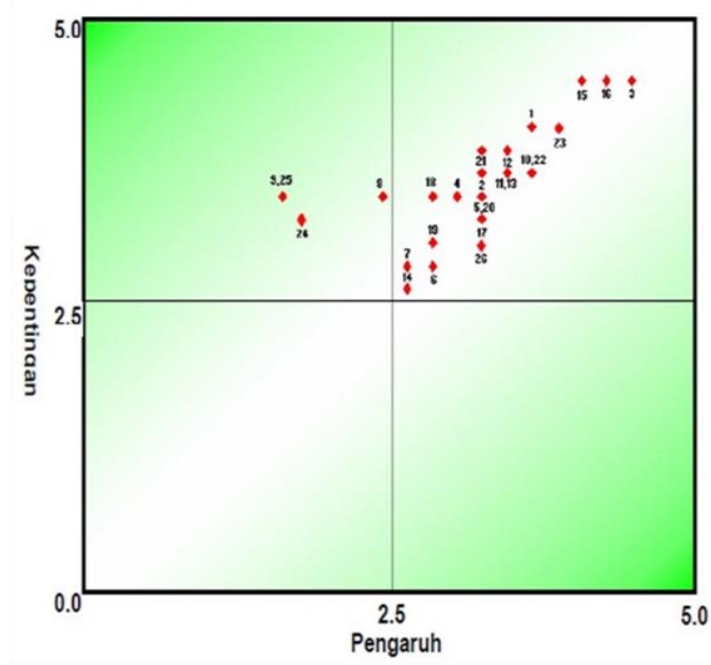

Gambar 6. Kuadran nilai skor pengaruh dan kepentingan stakeholders, KEK Sei Mangkei, 2016.

Secara keseluruhan stakeholder tersebut memiliki pengaruh dan kepentingan yang tinggi dalam pengelolaan KEK Sei Mangkei. Secara umum stakeholder pemerintah memiliki peran sebagai regulator, manajemen penyelenggara (Badan Usaha dan Administrator) sebagai fasilitator dan evaluator dalam pengelolaan KEK Sei Mangkei. Matriks kuadran pemetaan stakeholder (Gambar.6) terlihat bahwa terdapat (22) stakeholder yang berada pada kuadran ke III (aktor), dimana terdapat 3 (tiga) stakeholder yang menunjukkan koordinat (grid) paling tinggi pengaruh maupun kepentingannya terhadap KEK Sei Mangkei, yaitu : Dewan Nasional, Administrator Kawasan (PTSP) dan Badan Usaha Pembangunan dan Pengelola (BUPP) - PT. Perkebunan Nusantara III (Persero).

Sedangkan pada kuadran ke II (subjek) terdapat 4 stakeholder, yaitu LSM, OKP/ ORMAS, Masyarakat sekitar, Konsumen dan Perguruan Tinggi/Lembaga Penelitian.. Stakeholder yang berada pada kuadran II pada dasarnya memiliki kepentingan yang tinggi dalam keberlanjutan eksistensi KEK Sei Mangkei tetapi pengaruhnya terhadap stakeholder lainnya tergolong rendah dalam pengelolaan KEK Sei Mangkei.

\section{Studi Kepentingan dan Pengaruh Stakeholder}

\section{Level Tujuan}

Hasil analisis pendapat para pakar terhadap 5 (lima) sub level tujuan tersebut diperoleh bahwa tujuan yang ingin dicapai dalam pengelolaan KEK Sei Mangkei menuju klaster industri terintegrasi dan berkelanjutan adalah sub level keberlanjutan lingkungan/ekologi dan keberlanjutan ekonomi dengan bobot tertinggi yaitu 0.236, keberlanjutan idustri dan teknologi dengan skor 0.195, keberlanjutan hukum dan kelembagaan 0.172, dan keberlanjutan sosial dengan bobot 0.161. Adapun nilai bobot masing-masing dimensi keberlanjutan seperti terlihat pada (Tabel 3.).

Tabel 3. Hasil analisis level tujuan strategi pengelolaan KEK Sei Mangkei, klaster industri hilir terintegrasi dan berkelanjutan.

\begin{tabular}{llc}
\hline No & \multicolumn{1}{c}{$\begin{array}{c}\text { Elemen } \\
\text { Level Hirarki }\end{array}$} & $\begin{array}{c}\text { Pendapat } \\
\text { Pakar }\end{array}$ \\
\hline $\begin{array}{l}\text { Tujuan } \\
\text { 1. Keberlanjutan }\end{array}$ & 0.236 \\
2. & Keberlanjutan Sosial & 0.161 \\
3. Keberlanjutan Ekonomi & 0.236 \\
4. $\begin{array}{l}\text { Keberlanjutan Hukum } \\
\text { dan Kelembagaan }\end{array}$ & 0.172 \\
5. Keberlanjutan Industri & 0.195 \\
\hline
\end{tabular}

Tingginya nilai skor tujuan keberlanjutan lingkungan/ekologi dibandingkan dengan tujuan lainnya menunjukkan bahwa keberlanjutan lingkungan/ekologi keberlanjutan ekonomi menjadi perhatian utama dan sangat penting dimasukkan kedalam perencanaan dan pelaksanaan kegiatan 
KEK Sei Mangkei. Karena keberlanjutan ekologi dan keberlanjutan ekonomi sebagai parameter dan asset utama yang menyediakan kebutuhan manusia. Hal ini sejalan dengan Sulaiman et al. (2008) keberlanjutan lingkungan/ekologi mengharuskan industri untuk memperhatikan arah hilir dan hulu dimana produk yang dihasilkan harus memenuhi persyaratan ramah lingkungan artinya, pertimbangan SDA dan energi harus senantiasa menjadi pertimbangan utama dalam setiap aktivitas industri dalam meningkatkan nilai ekonomi (value added).

\section{Level Kriteria}

Pengelolaan KEK Sei Mangkei yang terintegrasi dan berkelanjutan secara lingkungan/ekologi menunjukkan adanya keterkaitan dan ketergantungan antara beberapa industri sehingga pembangunan instalasi pengelolaan air limbah (IPAL) atau waste water treatment plant (WWTP) kapasitas 250 $\mathrm{m}^{3} /$ jam di KEK Sei Mangkei sebagai suatu kesatuan dari berbagai kegiatan aktifitas produksi industri, dilakukan secara terpadu, menyeluruh yang mencakup pertimbangan kualitas dan kuantitas limbah menjamin terwujudnya keserasian, keselarasan, dan keseimbangan serta kelestarian kemampuan daya dukung sumber alam dengan memperlihatkan kepentingan masa depan. Meningkatnya ketersediaan lapangan kerja berdampak positif terhadap distribusi kesejahteraan dan pendapatan masyarakat sehingga semakin besar kesempatan masyarakat untuk memperoleh menikmati pendidikan yang pada akhirnya menghasilkan tenaga kerja yang potensial dengan pendidikan yang berkualitas di bidangnya sehingga stabilitas sosial dalam KEK Sei Mangkei dapat terjamin. Pertumbuhan industri dan UKM yang sehat, dengan adanya KEK Sei Mangkei klaser industri diharapkan mampu mendorong terbentuknya beberapa industri kecil menengah (IKM) yang didirikan oleh mayarakat secara swadaya dengan bantuan modal dari pihak industri. Sehingga dengan adanya UKM akan mampu memberikan konstribusi lebih kepada pemerintah daerah (PAD) serta pendapatan domestik bruto (PDB) nasional (Wahidi 2014).

Tabel 4. Hasil analisis level kriteria strategi pengelolaan KEK Sei Mangkei, klaster industri hilir terintegrasi dan berkelanjutan.

$\begin{array}{cc}\text { No } & \text { Elemen } \\ \text { Level Hirarki } & \text { Pendapat } \\ \text { Pakar }\end{array}$

Kriteria keberlanjutan lingkungan/ekologi

1. Kualitas dan daya dukung lingkungan yang sehat 0.302

2. Ketersediaan lahan/ ruang terbuka hijau (RTH) 30\% $\quad 0.129$

3. Minimalisasi kuantitas/kualitas limbah industri $\quad 0.370$

4. RTRW dan desain KEK Sei Mangkei berwawasan lingkungan $\quad 0.199$

Kriteria keberlanjutan sosial

$\begin{array}{ll}\text { 1. Stabilitas sosial } & 0.171\end{array}$

2. Kualitas pendidikan dan kesehatan masyarakat $\quad 0.129$

3. Distribusi kesejahteraan dan pendapatan masyarakat $\quad 0.229$

4. Penciptaan lapangan kerja

Kriteria keberlanjutan ekonomi

1. Pertumbuhan industri, UMKM, IKM yang sehat $\quad 0.500$

2. Kontribusi pada PAD dan PDB $\quad 0.500$

Kriteria keberlanjutan hukum dan kelembagaan

1. Kerjasama dan keterlibatan para stakeholder $\quad 0.134$

2. Ketersediaan dan kepastian hukum dan regulasi 0.328 
3. Kebijakan iklim investasi dan perizinan yang kondusif

4. Kebijakan insentif/disinsentif bagi pelaku industri pro lingk.

Sambungan Tabel 4...

Kriteria keberlanjutan industri dan teknologi

1. Ketersediaan bahan baku proses industri hilirisasi $\quad 0.187$

2. Efisiensi dan produktifitas industri (simbiosis mutualisme) $\quad 0.109$

3. Teknologi pengolahan dan pemanfaatan limbah $\quad 0.227$ komunikasi yang memadai

\section{Level Aktor}

Manajemen kelembagaan penyelenggara KEK Sei Mangkei (aktor utama) sesuai berdasarkan peraturan negara terkait kawasan ekonomi khusus sebagaimana diatur dalam Peraturan Pemerintah Nomor 2 Tahun 2011 tentang Penyelenggaraan Kawasan Ekonomi Khusus, Pasal 42 terkait pengelolaan KEK dilakukan oleh Adminstrator dan Badan Usaha Pengelola (penyelelenggara KEK) yang meliputi penegakkan aturan, seperti perizinan, penyelenggaraan, pengawasan dan pengendalian operasionalisasi KEK serta penyampaian laporan berkala dan insidental kepada Dewan Nasional atau Dewan Kawasan.

Tabel 5. Hasil analisis level aktor strategi pengelolaan KEK Sei Mangkei, klaster industri hilir terintegrasi dan berkelanjutan.

\begin{tabular}{|c|c|c|}
\hline No & $\begin{array}{c}\text { Elemen } \\
\text { Level Hirarki }\end{array}$ & $\begin{array}{l}\text { Pendapat } \\
\text { Pakar }\end{array}$ \\
\hline \multicolumn{3}{|c|}{ Level Aktor } \\
\hline & $\begin{array}{l}\text { Pemerintah (eksekutif } \\
\text { dan legislatif) }\end{array}$ & 3.466 \\
\hline 2. & $\begin{array}{l}\text { Investor/pelaku industri } \\
\text { Manajemen }\end{array}$ & 3.844 \\
\hline 3. & $\begin{array}{l}\text { kelembagaan } \\
\text { penyelenggara KEK Sei } \\
\text { Mangkei }\end{array}$ & 4.808 \\
\hline & Masyarakat sekitar & 2.920 \\
\hline & $\begin{array}{l}\text { Badan } \\
\text { Litbang/Perguruan }\end{array}$ & 1.368 \\
\hline
\end{tabular}

\author{
tinggi \\ LSM Lingkungan, Serikat, \\ OKP-Ormas,dsb \\ 1.595
}

\section{Level Aktor}

Berkaitan dengan alternatif pemilihan kebijakan tujuan yang ingin dicapai, serta peran aktor dalam pengelolaan KEK Sei Mangkei menuju klaster industri terintegrasi dan berkelanjutan, berbagai pilihan strategi yang dapat dilakukan meliputi (1) Menerapkan kebijakan investasi yang kondusif serta mengembangkan strategi Pro pelaku industri dalam negeri dan masyarakat lokal sebagai komponen eksistensi KEK dengan nilai 0.285, (2) Pembangunan dan pengembangan KEK Sei Mangkei berdasarkan spesifikasi klaster industri dan manajemen pengelolaan lingkungan kawasan berbasis ISO (International Organization for Standardization) dengan nilai 0.262, (3) Meningkatkan supremasi hukum dan kelembagaan penyelenggara KEK Sei Mangkei yang menjunjung nilai-nilai pembangunan berkelanjutan (PB) dengan nilai 0.231, dan (4) Menerapkan konsep CSR terpadu dan community development serta pemberian penghargaan-hukuman bagi pelaku industri yang pro-aktif pembangunan berkelanjutan (PB) dengan nilai 0.222. Selanjutnya dianalisis berdasarkan pendapat pakar. 
Tabel 6. Hasil analisis level pilihan strategi pengelolaan KEK Sei Mangkei, klaster industri hilir terintegrasi dan berkelanjutan .

\begin{tabular}{|c|c|c|}
\hline No & $\begin{array}{c}\text { Elemen } \\
\text { Level Hirarki }\end{array}$ & $\begin{array}{l}\text { Pendapat } \\
\text { Pakar }\end{array}$ \\
\hline \multicolumn{3}{|c|}{$\begin{array}{l}\text { Strategi pengelolaan KEK Sei Mangkei klaster industri hilir } \\
\text { terintegrasi dan berkelanjutan }\end{array}$} \\
\hline 1. & $\begin{array}{l}\text { Pembangunan dan pengembangan KEK Sei Mangkei berdasarkan } \\
\text { spesifikasi klaster industri dan manajemen pengelolaan } \\
\text { lingkungan kawasan berbasis ISO (International Organization for } \\
\text { Standardization) }\end{array}$ & 0.262 \\
\hline 2. & $\begin{array}{l}\text { Menerapkan kebijakan investasi yang kondusif serta } \\
\text { mengembangkan strategi Pro pelaku industri dalam negeri dan } \\
\text { masyarakat lokal sebagai komponen eksistensi KEK. }\end{array}$ & 0.285 \\
\hline 3. & $\begin{array}{l}\text { Meningkatkan supremasi hukum dan kelembagaan } \\
\text { penyelenggara KEK Sei Mangkei yang menjunjung nilai-nilai } \\
\text { pembangunan berkelanjutan (PB). }\end{array}$ & 0.231 \\
\hline 4. & $\begin{array}{l}\text { Menerapkan konsep CSR terpadu dan community development } \\
\text { serta pemberian penghargaan-hukuman bagi pelaku industri } \\
\text { yang pro-aktif terhadap pembangunan berkelanjutan (PB). }\end{array}$ & 0.222 \\
\hline
\end{tabular}

Berdasarkan hasil kombinasi dan sintesis terhadap seluruh pakar, menunjukkan diagram batang di bawah hasil pengolahan data AHP (Software Expert Choice 11).

Combined instance -. Synthesis with respect to: Strategi Pengelolaan KEK Sei Mangkei Terintegrasi dan Berkelaniutan

$$
\text { Overall Inconsistency }=.01
$$

Pembangunan dan pengembangan KEK dan manajemen pengelolaan lingkungan berbasis 150 Menerapkan kebijakan investasi yang kondusit serta mengembangkan stratergi pro pelaku industri da.. Meningkatkan supremasi hukum dan kelembagaan penyelenggara KEK yang meniuniung nilai-nilai p... Menerapkan konsep CSR terpadu dan community development

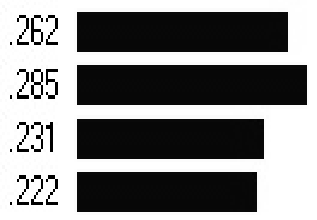

Gambar 7. Diagram nilai skor AHP sebagai prioritas strategi dan kebijakan pengeloloaan KEK Sei Mangkei terintegrasi berkelanjutan, 2016.

\section{SIMPULAN}

Kondisi eksisting pembangunan KEK Sei Mangkei masih lebih dominan areal tegakan perkebunan sawit dan karet PT. Perkebunan Nusantara III (Persero), hal ini membutuhkan strategi untuk mengakselerasi pembangunan dan menarik minat investor di KEK Sei Mangkei. Matriks kuadran pemetaan stakeholder terlihat bahwa terdapat (23) stakeholder yang berada pada kuadran ke III (aktor). Sedangkan pada kuadran ke II (subjek) terdapat 4 stakeholder. Pilihan strategi yang dapat dilakukan meliputi (1) Menerapkan kebijakan investasi yang kondusif serta mengembangkan strategi Pro pelaku industri dalam negeri dan masyarakat lokal sebagai komponen eksistensi KEK, dengan nilai 0.285 , (2) Pembangunan dan pengembangan KEK Sei Mangkei berdasarkan spesifikasi klaster industri dan manajemen pengelolaan lingkungan kawasan berbasis ISO (International 
Organization for Standardization), dengan nilai 0.262, (3) Meningkatkan supremasi hukum dan kelembagaan penyelenggara KEK Sei Mangkei yang menjunjung nilai-nilai pembangunan berkelanjutan, dengan nilai 0.231 (4) Menerapkan konsep CSR terpadu dan commdev serta pemberian penghargaanhukuman bagi pelaku industri yang pro aktif terhadap pembangunan berkelanjutan, dengan nilai $(0.222)$.

\section{DAFTAR PUSTAKA}

Alkadri. 2011. Kebijakan Pengembangan Kawasan Ekonomi Khusus (KEK) Di Provinsi Banten. J Sains dan Teknologi Indonesia Vol. 13, No. 1, HIm.7-13.

Anugrahini DN. 2015. Perkembangan Kawasan Ekonomi Khusus (KEK) Batam Dalam Pemberlakuan Free Trade Zone (FTZ). J Ilmu Hubungan Internasional, 3 (3): 559-570.

[Bappenas] Badan Perencanaan Pembangunan Nasional. 2014. Buku I : Agenda Pembangunan Nasional RPJMN 2015-2019. Jakarta (ID): Badan Perencanaan Pembangunan Nasional.

Deepak S. 2012. s In India: Investment, Trade, Employment Generation and Impact Assessment. Gokhale (IN) : Gokhale Institute of Politics and Economics.

Dharmayanti I. 2015. Desain model pengembangan klaster industri hilir kelapa sawit di kawasan industri sei mangkei [disertasi]. Bogor (ID) : Institut Pertanian Bogor.

Dharmayanti I, Hardjomidjojo H, Fauzi AM, Mulyadi D. 2015. Sustainability Analysis of Sei Mangkei Palm Oil Based Industrial Cluster. J Economics Sustainable Development. 6(4):176-183.

Falatehan F. 2015. Teknik Pengambilan Keputusan Menggunakan Analytic Hierarchy Process (AHP). Bogor (ID) : Program Studi Manajemen
Pembangunan Daerah. Sekolah Pascasarjana Institut Pertanian Bogor.

[GAPKI] Gabungan Pengusaha Kelapa Sawit Indonesia. 2014. Industri Minyak Sawit Indonesia Menuju 100 Tahun NKRI. GAPKI (ID) : Edisi pertama.

Kementerian Koordinator Bidang Perekonomian. 2011. Masterplan Percepatan dan Perluasan Pembangunan Ekonomi Indonesia (MP3EI). IndoPacific Edelman (ID) : Cetakan pertama 2011.

Khan N, Varshney P K. 2012. Future Prospects of $\mathrm{S}$ In India In Industrial Sector, J International of Marketing, Financial Services \& Management Research ,Vol.1, Pp. 140-151.

Kristanto P. 2013. Ekologi Industri Indonesia. Yogyakarta (ID) : Penerbit CV. Andi Offset. Edisi Kedua.

Kurniawan W. 2011. Urgensi Pembangunan Agroindustri Kelapa Sawit Berkelanjutan Untuk Mengurangi Pemanasan Global. J Teknik Industri, ISSN:1411-6340.

Lingga D, Pratomo WA. 2013. Persepsi Masyarakat Terhadap Pengembangan Kawasan Ekonomi Khusus Sei Mangkei Sebagai Klaster Industri. Jurnal Ekonomi dan Keuangan, Vol.1, No.2.

Listiyorini E. 2006. Kawasan Ekonomi Khusus. Jurus Baru Tarik Investor. Medan (ID) : SK. Harian Analisa.

Marimin. 2005. Pengambilan Keputusan Kriteria Majemuk. Jakarta (ID) : Penerbit Grasindo.

Pemerintah Republik Indonesia. 2012. Peraturan Pemerintah Nomor 29 Tahun 2012 tentang Penetapan Kawasan Ekonomi Khusus Sei Mangkei. Jakarta (ID): Sekretaris Negara. 
Pemerintah Republik Indonesia. 2009. Undang-undang Nomor 32 Tahun 2009 tentang Perlindungan dan Pengelolaan Lingkungan Hidup. Jakarta (ID): Sekretaris Negara.

Pemerintah Republik Indonesia. 2009. Undang-undang Nomor 39 Tahun 2009 tentang Kawasan Ekonomi Khusus. Jakarta (ID): Sekretaris Negara.

Pemerintah Republik Indonesia. 2011. Peraturan Pemerintah Nomor 02 Tahun 2011 tentang Penyelenggaraan Kawasan Ekonomi Khusus. Jakarta (ID): Sekretaris Negara.

Pemerintah Republik Indonesia. 2012. Peraturan Pemerintah Nomor 29 Tahun 2012 tentang Penetapan Kawasan Ekonomi Khusus Sei Mangkei. Jakarta (ID): Sekretaris Negara.

Purba H. 2006. Kawasan Ekonomi Khusus (KEK) Fenomena Global: Suatu Kajian Aspek Hukum. J Equality, Vol. 11 No. 2.

Rachman NR, Yanuardy D. 2014. Master Plan Percepatan Dan Perluasan Krisis Sosial-Ekologis Indonesia. Yogyakarta (ID) : Penerbit Tanah Air Beta.

Richardson, Harry W. 1991. Dasar-dasar Ilmu Ekonomi Regional. Jakarta (ID) : Penerbit Lembaga Penerbit Fakultas Ekonomi Universitas Indonesia.

Sekretariat Dewan Nasional Kawasan Ekonomi Khusus, Kementerian BUMN: kek.ekon.go.id/index.php/in/kek -indonesia.html

Sihaloho T, Muna N. 2013. Pusat Penelitian dan Pengembangan Iklim Usaha Perdagangan: Kajian Dampak Ekonomi Pembentukan Kawasan Ekonomi Khusus. Jakarta (ID): Kementerian Perdagangan.
Sitorus HP, Siagian S, Manurung K. 2014. MP3EI: Proyek Hilirisasi Sawit dan Eksploitasi Buruh Sawit di Perkebunan Sumatera Utara. Working Paper Sajogyo Institute, No.18, 2014.

Soekartawi. 2003. Nilai Strategis Industri Sawit. J Pusat Analisa Sosial Ekonomi dan Kebijakan. Badan Penelitian dan Pengembangan Pertanian.

Sulaiman F, Asep S, Rizal S, Alinda FMZ. 2008. Strategi Pengelolaan Kawasan Industri Cilegon Menuju Eco Industrial Park. J Perenc Wil dan Kota. 19(2) Agustus 2008 : 37-57.

Sulaiman F. 2009. Strategi pengelolaan kawasan industri cilegon menuju eco industrial park (studi pada kawasan industri cilegon propinsi banten) [disertasi]. Bogor (ID) : Institut Pertanian Bogor.

Tarigan R. 2005. Ekonomi Regional. Jakarta (ID) : Penerbit Bumi Aksara.

Tim Kerja Sekretariat KP3EI. 2013. Laporan Perkembangan Pelaksanaan MP3EI. Jakarta (ID) : Kementerian Koordinator Bidang Perekonomian.

Wanggai VV. 2011. Mengelola Strategi Pembangunan Berdimensi Kewilayahan. J Sekretariat Negara Republik Indonesia, Nomor 20.

[WCED] World Commission on Environment and Development. 1987. Sustainable Development : From Bruntland to Rio 2012. New York (US) : International Institute for Sustainable Development (IISD).

Wahidi RD. 2014. Kawasan Industri Indonesia : Sebuah Konsep Perencanaan dan Aplikasinya. Bogor (ID) : Penerbit CV. Biografika. Edisi Terbaru. 